\title{
Atividade de plasmina e plasminogênio no leite longa vida com alta e baixa contagem de células somáticas durante 0 armazenamento
}

\author{
Activity of plasmin and plasminogen in ultra high temperature milk with high \\ and low somatic cell counts during storage
}

\author{
Carlos Humberto Corassin ${ }^{\mathrm{I}}$ Roice Eliana Rosim ${ }^{\mathrm{I}}$ \\ Carlos Augusto Fernandes de Oliveira ${ }^{I^{*}}$
}

\section{RESUMO}

O objetivo deste estudo foi avaliar o efeito da contagem de células somáticas (CCS) do leite na atividade de plasmina e plasminogênio durante o periodo de armazenamento do leite longa vida integral. Os leites crus foram categorizados em grupos de CCS de baixa (342.000487.000 células $\mathrm{mL}^{-1}$ ) e alta contagem (603.000-808.000 células $\left.m L^{-1}\right)$. Dois lotes de leite longa vida em cada categoria de CCS foram analisados para determinação de plasmina e plasminogênio após 10, 30, 60, 90 e 120 dias de armazenamento em temperatura ambiente. Para a fabricação do leite longa vida, o leite cru foi submetido à pasteurização rápida seguida da esterilização industrial do leite por injeção de vapor pelo método direto e embalagem asséptica do produto. A CCS não apresentou efeitos sobre as características físico-quimicas do leite cru, e nem sobre a atividade de plasmina e plasminogênio nos leites cru e longa vida, armazenados por 120 dias. Entretanto, independentemente da CCS, a atividade de plasmina e plasminogênio aumentou no leite longa vida ao longo do armazenamento, indicando a possibilidade de aumento da proteólise no produto durante sua vida de prateleira.

Palavras-chave: leite UAT, CCS, qualidade, proteólise.

\section{ABSTRACT \\ This study aimed to evaluate the effect of somatic cell counts (SCC) in milk on plasmin and plasminogen activities of ultra high temperature (UHT) milk during storage. Raw milks were categorized in SCC groups of low (342,000-487,000 cells $\left.m L^{-1}\right)$ and high cells (603,000-808,000 cells $\left.\mathrm{mL}^{-1}\right)$. Two replicates of UHT milks within each SCC category were analyzed for plasmin and plasminogen activities after 10, 30, 60, 90 and 120 days of storage at room temperature. For manufacture of UHT milk, raw milk was pasteurized and sterilized by direct}

vapor injection process, followed by aseptic packaging. SCC had no effect on physical-chemical characteristics of raw milk, and on plasmin or plasminogen activities in raw and UHT milks during 120 days of storage. However, independently of the SCC in raw milk, the activity of plasmin and plasminogen increased in UHT milk during storage, hence indicating a possible increase in proteolysis in the product during its shelflife.

Key words: UHT milk, SCC, quality, proteolysis.

\section{INTRODUÇÃO}

Os tratamentos a temperaturas ultra-altas têm experimentado uma expansão espetacular nas últimas décadas e, atualmente, aplicam-se a muitos setores da indústria alimentícia, principalmente às indústrias lácteas, para esterilização industrial do leite e obtenção de produtos de longa duração (EARLY, 1998). Entretanto, com esta tecnologia, surgiram também novos desafios, entre eles, a manutenção da qualidade do produto durante a vida de prateleira. Neste contexto, alterações da estrutura física do leite, entre elas a gelatinização, constituem um dos principais fatores que podem afetar o tempo de vida útil do leite longa vida (FERNANDES et al., 2008). Dentre os fatores que influenciam a gelatinização do leite, destaca-se, principalmente, a ação de enzimas proteolíticas, as quais em grande parte são termoestáveis, permanecendo ativas mesmo após os processos usuais de pasteurização ou esterilização do leite. Efeitos

'Departamento de Engenharia de Alimentos, Faculdade de Zootecnia e Engenharia de Alimentos, Universidade de São Paulo (USP), Av. Duque de Caxias Norte, 225, 13635-900, Pirassununga, SP, Brasil. E-mail: carlosaf@usp.br. *Autor para correspondência. 
adicionais dessas enzimas manifestam-se também na forma de alterações no sabor dos produtos lácteos (RENEAU \& PACKARD, 1991), de modo que o tempo de prateleira dos produtos lácteos de longa duração pode ser estimado pela degradação enzimática (MUIR, 1996).

Existem no leite 50 diferentes tipos de enzimas nativas, porém a principal atividade proteolítica endógena no leite é decorrente da ação da plasmina, enzima normalmente associada à fração de caseína (RICHARDSON, 1983). A plasmina do leite é idêntica à plasmina do sangue, diferindo apenas no peso molecular (MUIR, 1996). A proteólise originária da plasmina perfaz aproximadamente $90 \%$ da proteólise total (BARRY \& DONNELLY, 1981). O plasminogênio, que também está presente no leite, pode ser prontamente ativado e convertido em plasmina (RICHARDSON, 1983). VERDI \& BARBANO (1991) evidenciaram que as células somáticas apresentam esta capacidade de conversão, resultando em proteólise da caseína. Esse fato confirma a associação entre a alta contagem de células somáticas (CCS) e o aumento da atividade proteolítica da plasmina, uma vez que os leucócitos e as enzimas extracelulares bacterianas não são capazes de converter o plasminogênio em plasmina.

$\mathrm{O}$ aumento da CCS está relacionado à mastite em vacas leiteiras, uma vez que durante a evolução da doença há um influxo maior dessas células para a glândula mamária, conduzindo à elevação do seu número no leite e, consequentemente, de enzimas naturalmente presentes nessas células, sobretudo de plasmina (POLITIS et al., 1992). No leite com baixa CCS, pode-se observar uma taxa normal de ativação do plasminogênio para plasmina. No entanto, uma taxa acentuadamente maior ocorre em leites com alta CCS (DE RHAM \&ANDREWS, 1982). KENNEDY \& KELLY (1997) demonstraram que a atividade da plasmina no leite cru com 800.000 células $\mathrm{mL}^{-1}$ foi aproximadamente duas vezes maior que no leite com CCS menor que 150.000 células $\mathrm{mL}^{-1}$.

A plasmina exerce forte ação proteolítica sobre as frações de caseína $a_{S 1}$, as 2 e b, sendo que essa atividade aumenta com a severidade da mastite e, consequentemente, com o aumento da CCS no leite (BASTIAN \& BROWN, 1996). Entretanto, o armazenamento, o tratamento térmico e o pH estão entre os mais importantes fatores afetando o sistema plasmina no leite e derivados (BURBRINK \& HAYES, 2006). A estabilidade térmica da plasmina é $\mathrm{pH}$ dependente, sendo estável à pasteurização em $\mathrm{pH}$ ácido ou neutro, e rapidamente inativada em $\mathrm{pH}$ alcalino (MUIR, 1996). Os ativadores de plasminogênio são estáveis ao $\mathrm{pH}$ e à temperatura e estão associados predominantemente à fração de caseína (RICHARDSON, 1983).

Considerando a relação direta entre a CCS e atividade enzimática do leite, o presente trabalho teve como objetivo avaliar as atividades de plasmina e plasminogênio durante o período de armazenamento do leite longa vida integral, produzido a partir de leite contendo diferentes níveis de células somáticas.

\section{MATERIAL E MÉTODOS}

O leite utilizado no experimento foi proveniente de usina de beneficiamento, localizada no município de Casa Branca/SP, utilizando-se quatro lotes de leite longa vida produzidos no período de agosto a dezembro de 2008. Antes do início de cada lote de leite a ser processado (8.000-15.000 $\left.\mathrm{L} \mathrm{lote}^{-1}\right)$, foram colhidas amostras em duplicata de $600 \mathrm{~mL}$ do leite cru armazenado no tanque-silo. Cada amostra foi composta por $10 \mathrm{sub}$ amostras de $60 \mathrm{~mL}$ de leite, coletadas em intervalos de cerca de $10 \mathrm{~min}$, durante a transferência do leite do tanque-silo para o tanque de equilíbrio do pasteurizador. Imediatamente após a coleta, as amostras de leite cru foram submetidas à determinação de $\mathrm{pH} \mathrm{e}$ acidez titulável (IAL, 1985), além de sólidos totais, gordura, proteína total e lactose, utilizando-se um analisador automático (Boeco, Alemanha). Em seguida, as amostras foram enviadas para realização da contagem de células somáticas, através de contador eletrônico (Bentley, Chaska, Minnesota, USA).

O leite cru foi submetido à pasteurização rápida (HT-ST) em trocadores de calor a placas, sendo pré-aquecido a $50^{\circ} \mathrm{C}$, clarificado em centrífuga, aquecido a $72-75^{\circ} \mathrm{C}$ por $15-20$ segundos, imediatamente resfriado a $4^{\circ} \mathrm{C}$ e estocado temporariamente em balão isotérmico até o início do processamento para obtenção do leite longa vida. A esterilização industrial do leite pasteurizado foi realizada em um sistema contínuo, construído pela empresa Tetra-Pak. Nesse sistema, o leite tratado resfriado foi previamente aquecido a $85^{\circ} \mathrm{C}$ em trocadores tubulares, seguindo posteriormente na linha para injeção de vapor superaquecido até atingir a temperatura de $132-135^{\circ} \mathrm{C}$, por 2-8 segundos. Em seguida, o leite foi submetido à evaporação em câmara de vácuo parcial (onde sofreu um $1 \stackrel{0}{\circ}$ resfriamento até cerca de $70^{\circ} \mathrm{C}$ ) e homogeneizado em homogeneizadora de dois estágios, retornando ao trocador tubular para um $2^{\circ}$ resfriamento à temperatura de cerca de $20^{\circ} \mathrm{C}$. O produto foi embalado automaticamente em embalagens assépticas cartonadas de 1L, em sistema de torre. Todas as unidades produzidas em cada lote ficaram retidas na usina até o término do período de observação de amostras do lote, mantidas em estufa a $35^{\circ} \mathrm{C}$ por sete dias.

Após a liberação de cada lote pela empresa, seguindo as normas do regulamento técnico de identidade e qualidade do leite UAT/UHT (BRASIL, 1997), foram reservadas 10 unidades do produto para fins de análises laboratoriais, as quais foram armazenadas à temperatura ambiente $\left(22-27^{\circ} \mathrm{C}\right)$ e 
protegidos da incidência solar durante 120 dias. As análises foram efetuadas nos quatro lotes de leite longa vida, aos 10, 30, 60, 90 e 120 dias após a fabricação.

As atividades da plasmina e do plasminogênio foram determinadas através da metodologia descrita por SAINT-DENIS et al. (2001). Para avaliar a atividade da plasmina, amostras de leite $(1 \mathrm{~mL})$ foram pré-incubadas por $10 \mathrm{~min} . \mathrm{a} 37^{\circ} \mathrm{C} \mathrm{com} 1 \mathrm{~mL}$ de tampão Tris-HCl 100mM (pH 8,0), contendo ácido e-aminocapróico $8 \mathrm{mM} \mathrm{e} \mathrm{NaCl} 0,4 \mathrm{M}$ e gelatina $\left(4 \mathrm{~g} \mathrm{~L}^{-1}\right)$ com objetivo de dissociar a plasmina das micelas de caseína. Na determinação da atividade do plasminogênio, essa proenzima é convertida em plasmina ativa (KORYCKA-DAHL et al., 1983; ROLLEMA et al., 1983), pela incubação de $1 \mathrm{~mL}$ de leite, em presença de solução de uroquinase, por $60 \mathrm{~min}$ a $37^{\circ} \mathrm{C}$. A atividade da plasmina e a atividade derivada após a ativação do plasminogênio pela uroquinase foram determinadas quantificando-se a concentração de 7-amido-4-metil cumarina (AMC), um produto fluorescente liberado pela plasmina a partir de um peptídeo (PIERZCHALA et al., 1979). A quantificação de AMC foi realizada em um detector de fluorescência (Shimadzu, Japão), equipado com célula para cubetas de $1 \mathrm{~cm}$ de percurso óptico, utilizando-se excitação a $370 \mathrm{~nm}$ e emissão a $440 \mathrm{~nm}$. A curva de calibração foi preparada utilizando-se as soluções padrão contendo $0,5,1,25,2,5$ e $5,0 \mu \mathrm{g} \mathrm{mL}^{-1}$ de plasmina, preparadas de acordo com SAINT-DENIS et al. (2001). Os resultados foram expressos em unidades Sigma (US), considerando $1,0 \mathrm{US}=1,0 \mathrm{mM}$ AMC liberado no ensaio.

Os quatro lotes (repetições) de leite longa vida estudados foram categorizados em dois grupos, de baixa e alta CCS. Desse modo, o delineamento utilizado para avaliar os efeitos da CCS sobre a atividade enzimática no leite longa vida durante o armazenamento foi o de blocos casualizados com medidas repetidas no tempo em cinco ocasiões $(10,30$, 60, 90 e 120 dias de armazenamento). A análise estatística das atividades de plasmina e plasminogênio foi realizada utilizando-se o procedimento proc mixed do $\operatorname{SAS}^{\circledR}$ (SAS, 2004), sendo o posterior estudo de regressão feito através de contrastes ortogonais. As diferenças entre as médias dos grupos foram avaliadas pelo teste de Tukey ao nível de 5\% de significância.

\section{RESULTADOS E DISCUSSÃO}

A tabela 1 apresenta os resultados obtidos nas análises físico-químicas e de atividade de plasmina e plasminogênio no leite cru utilizado na fabricação do leite longa vida. As contagens médias de células somáticas nos leites categorizados como baixa e alta
Tabela 1 - Contagem de células somáticas (CCS), características físicoquímicas e atividades de plasmina e plasminogênio no leite cru dos grupos de alta e baixa $\mathrm{CCS}^{1}$.

\begin{tabular}{lll}
\hline Parâmetros & Baixa CCS & Alta CCS \\
\hline $\begin{array}{l}\text { Contagem de células somáticas } \\
\left(\text { Log células } \mathrm{mL}^{-1}\right)\end{array}$ & $5,61 \pm 0,11^{\mathrm{b}}$ & $5,85 \pm 0,09^{\mathrm{a}}$ \\
$\mathrm{pH}$ & $6,41 \pm 0,31$ & $6,65 \pm 0,17$ \\
Acidez $\left({ }^{\circ} \mathrm{D}\right)$ & $16,5 \pm 0,50$ & $16,5 \pm 0,50$ \\
Proteína (\%) & $3,45 \pm 0,03$ & $3,47 \pm 0,01$ \\
Gordura (\%) & $3,78 \pm 0,03$ & $3,24 \pm 0,19$ \\
Lactose $(\%)$ & $4,51 \pm 0,04$ & $4,53 \pm 0,01$ \\
Sólidos totais $(\%)$ & $12,46 \pm 0,04$ & $11,96 \pm 0,17$ \\
Plasmina (US $\left.{ }^{2}\right)$ & $173,50 \pm 1,50$ & $179,50 \pm 4,50$ \\
Plasminogênio $\left(\mathrm{US}^{2}\right)$ & $145,50 \pm 8,50$ & $128,50 \pm 1,50$ \\
\hline
\end{tabular}

${ }^{1}$ Resultados expressam a média \pm desvio padrão de duas amostras analisadas em duplicata.

${ }^{2}$ US - Unidade Sigma (1,0US=1,0mM 7-amido-4-metil cumarina (AMC). a,b Médias seguidas de letras distintas, em uma mesma linha, diferem pelo teste de Tukey $(\mathrm{P}<0,05)$.

CCS foram diferentes $(\mathrm{P}<0,05)$, sendo 408.110 células $\mathrm{mL}^{-1}\left(5,61 \mathrm{Log}\right.$ células $\left.\mathrm{mL}^{-1}\right)$ e 698.014 células $\mathrm{mL}^{-1}$ $\left(5,85 \mathrm{Log}\right.$ células $\left.\mathrm{mL}^{-1}\right)$, respectivamente. Não houve diferença $(\mathrm{P}>0,05)$ nos valores de $\mathrm{pH}$, acidez titulável, gordura, proteína total, lactose e sólidos totais obtidos nos leites com baixa e alta CCS. Além disso, os valores obtidos nas análises estiveram de acordo com a legislação, apresentando variações semelhantes as observadas por VIDAL-MARTINS et al. (2005) para o leite cru, utilizado para fabricação de leite longa vida. Os níveis de plasmina e plasminogênio também não diferiram $(\mathrm{P}>0,05)$ nos dois tipos de leite cru, o que contraria os dados reportados por KENNEDY \& KELLY (1997), os quais observaram maior atividade da plasmina no leite cru com 800.000 células $\mathrm{mL}^{-1}$, quando comparado ao leite com 150.000 células $\mathrm{mL}^{-1}$. Ressaltese que no presente estudo, a diferença entre a CCS dos tipos de leite foi menor, em relação aos níveis utilizados no estudo de KENNEDY \& KELLY (1997).

A ausência de efeitos da CCS $(\mathrm{P}>0,05)$ sobre a atividade de plasmina e plasminogênio também foi observada durante o armazenamento do leite longa vida, conforme está apresentado nas tabelas 2 e 3, respectivamente. No entanto, observou-se um aumento linear $(\mathrm{P}<0,05)$ da atividade de plasmina $\mathrm{e}$ plasminogênio no leite longa vida durante o armazenamento por 120 dias. A presença de plasmina no leite longa vida evidencia a sua capacidade de resistência ao calor de esterilização do leite, conforme relatado por outros autores (KORYCKA-DAHL et al., 1983; VERDI \& BARBANO, 1988; BASTIAN \& BROWN, 1996) com relação à pasteurização do leite. Adicionalmente, o aumento da atividade de plasmina no leite longa vida ao longo do armazenamento (Tabela 2) 
é preocupante, tendo em vista a possibilidade de aumento da atividade proteolítica durante a vida de prateleira do produto, conforme relatado no estudo de MANJI et al. (1986).

No presente trabalho, a atividade de plasminogênio também aumentou durante o armazenamento do leite longa vida (Tabela 3), discordando dos relatos de RICHARDSON (1983), segundo o qual a concentração de plasminogênio decresce durante o armazenamento do leite cru ou pasteurizado, e de VERDI \& BARBANO (1991), os quais observaram que a atividade de plasminogênio pode ser anulada pelo aquecimento do leite a $63^{\circ} \mathrm{C}$ por 30 minutos. Contudo, não há relatos prévios sobre a atividade de plasminogênio no leite longa vida, o que dificulta a comparação dos resultados obtidos no presente estudo. O aumento da atividade de plasminogênio foi coerente com o aumento concomitante de plasmina no leite longa vida ao longo do armazenamento. VERDI \& BARBANO (1991) observaram que as células somáticas constituem os principais fatores responsáveis pela conversão de plasminogênio em plasmina. Desse modo, considerando que o conteúdo das células somáticas permanece no leite após o processamento, estima-se que a principal contribuição para o aumento da atividade de plasmina no leite longa vida armazenado por 120 dias tenha sido o plasminogênio, ativado por constituintes das células somáticas (DE RHAM \& ANDREWS, 1982). Entretanto, no presente estudo, não foram observados efeitos da CCS isoladamente, ou de interações entre CCS e o tempo de armazenamento

Tabela 2 - Atividade de plasmina no leite longa vida durante 120 dias de armazenamento ${ }^{1}$.

\begin{tabular}{|c|c|c|c|c|c|}
\hline \multirow[b]{2}{*}{$\mathrm{CCS}^{3}$} & \multicolumn{5}{|c|}{ 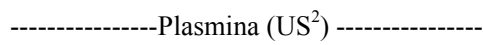 } \\
\hline & Dia 10 & Dia 30 & Dia 60 & Dia 90 & $\begin{array}{l}\text { Dia } \\
120\end{array}$ \\
\hline Baixa & 179,5 & 199,0 & 209,5 & 233,0 & 240,0 \\
\hline Alta & 196,0 & 194,5 & 201,5 & 224,5 & 234,0 \\
\hline Erro padrão & 7,90 & 5,59 & 3,52 & 4,5 & 4,14 \\
\hline Fonte de variação & \multicolumn{5}{|c|}{-----P valor (nível descritivo do teste) ----- } \\
\hline $\mathrm{CCS}$ & \multicolumn{5}{|c|}{00,7478} \\
\hline Dia & \multicolumn{5}{|c|}{$00,0127^{*}$} \\
\hline CCS*Dia & \multicolumn{5}{|c|}{00,5656} \\
\hline
\end{tabular}

${ }^{1}$ Resultados expressam a média de duas amostras analisadas em duplicata.

${ }^{2}$ US - Unidade Sigma (1,0US=1,0mM 7-amido-4-metil cumarina (AMC).

${ }^{3}$ CCS nos grupos: $342.000-487.000$ células $\mathrm{mL}^{-1}$ (baixa) e 603.000-808.000 células $\mathrm{mL}^{-1}$ (alta).

*Efeito linear: $\mathrm{y}=0,4671 \mathrm{x}+182,19\left(\mathrm{R}^{2}=0,783\right)$.
Tabela 3 - Atividade de plasminogênio no leite longa vida durante 120 dias de armazenamento ${ }^{1}$.

\begin{tabular}{|c|c|c|c|c|c|}
\hline \multirow[b]{2}{*}{$\mathrm{CCS}^{3}$} & \multicolumn{5}{|c|}{-------Plasminogênio (US'2) -------- } \\
\hline & Dia 10 & Dia 30 & Dia 60 & Dia 90 & $\begin{array}{l}\text { Dia } \\
120\end{array}$ \\
\hline Baixa & 151,0 & 159,0 & 174,5 & 189,0 & 208,0 \\
\hline Alta & 146,5 & 161,5 & 167,0 & 186,5 & 196,5 \\
\hline Erro padrão & 1,38 & 1,25 & 3,15 & 1,31 & 5,25 \\
\hline Fonte de variação & \multicolumn{5}{|c|}{---- P valor (nível descritivo do teste) ---- } \\
\hline $\mathrm{CCS}$ & \multicolumn{5}{|c|}{0,3017} \\
\hline Dia & \multicolumn{5}{|c|}{$0,0007^{*}$} \\
\hline CCS*Dia & \multicolumn{5}{|c|}{0,5374} \\
\hline
\end{tabular}

${ }^{1}$ Resultados expressam a média de duas amostras analisadas em duplicata.

${ }^{2}$ US - Unidade Sigma (1,0US=1,0mM 7-amido-4-metil cumarina (AMC).

${ }^{3}$ CCS nos grupos: $342.000-487.000$ células $\mathrm{mL}^{-1}$ (baixa) e 603.000-808.000 células $\mathrm{mL}^{-1}$ (alta).

*Efeito linear: $y=0,4801 x+144,19\left(R^{2}=0,930\right)$.

$(\mathrm{P}>0,05)$, sobre a atividade de plasmina ou plasminogênio no leite longa vida.

$\mathrm{O}$ aumento da atividade de plasmina e plasminogênio durante $o$ armazenamento do leite longa vida pode acarretar um aumento da proteólise do produto, com possíveis modificações na viscosidade (VIDAL-MARTINS et al., 2005), inclusive a ocorrência de gelatinização (FERNANDES et al., 2008b). A atividade proteolítica dessas enzimas pode provocar também alterações no sabor dos produtos lácteos (RENEAU \& PACKARD, 1991), diminuindo o tempo de prateleira dos produtos lácteos de longa duração pela degradação enzimática. Ressalta-se a necessidade de estudos para avaliar a importância dos níveis de atividade de plasmina e plasminogênio constatadas no presente trabalho para as alterações físicas e químicas do leite longa vida durante a sua vida de prateleira.

\section{CONCLUSÃO}

As contagens médias de células somáticas observadas no leite ( 408.110 e 698.014 células $\mathrm{mL}^{-1}$ ) não apresentam efeitos sobre as características físico-químicas do leite cru e atividades de plasmina e plasminogênio nos leites cru e longa vida armazenados por 120 dias em temperatura ambiente. Entretanto, a atividade de plasmina e plasminogênio aumenta com o tempo de armazenamento, independentemente da CCS no leite, o que pode determinar um aumento da proteólise da caseína no leite longa vida ao longo da vida de prateleira. 


\section{AGRADECIMENTOS}

Os autores agradecem ao Conselho Nacional de Desenvolvimento Científico e Tecnológico (CNPq), pelo suporte financeiro - processo n. 152616/2007-1.

\section{REFERÊNCIAS}

BARRY, J.G.; DONNELLY, W.J. Casein compositional studies. II. The effect of secretory disturbance on casein composition in freshly drawn and aged bovine milks. Journal of Dairy Research, v.48, p.437-46, 1981. Disponível em: <http:// dx.doi.org/10.1017/S0022029900021919>. Acesso em: 15 fev. 2010. doi: $10.1017 / \mathrm{S} 0022029900021919$.

BASTIAN, E.D.; BROWN, R.J. Plasmin in milk and dairy products: an update. International Dairy Journal, v.6, p.435-457, 1996. Disponível em: <http://dx.doi.org/10.1016/ 0958-6946(95)00021-6>. Acesso em 18 fev. 2010. doi:10.1016/0958-6946(95)00021-6.

BRASIL. Regulamento técnico de identidade e qualidade do leite UHT/UAT. Portaria 370 de 4 de setembro de 1997. Brasília, Ministério da Agricultura. 1997. 9p.

BURBRINK, C.N.; HAYES, K.D. Effect of thermal treatment on the activation of bovine plasminogen. International Dairy Journal, v.16, p.580-505, 2006. Disponível em: <http:// dx.doi.org/doi:10.1016/j.idairyj.2005.08.017>. Acesso em 15 fev. 2010. doi: doi:10.1016/j.idairyj.2005.08.017.

DE RHAM, O.; ANDREWS, A.T. Qualitative and quantitative determination of proteolysis in mastitic milks. Journal of Dairy Science, v.49, p.587-96, 1982. Disponível em: <http:/ /dx.doi.org/doi:10.1017/S0022029900022731>. Acesso em 15 fev. 2010. doi: 10.1017/S0022029900022731.

EARLY, R. Tecnología de los productos lácteos. 2.ed. Zaragoza: Acribia, 1998. 459p.

FERNANDES, A.M. et al. Casein fractions of ultra high temperature milk with different somatic cell counts. Pesquisa Agropecuária Brasileira, v.43, p.149-152, 2008. Disponível em: $<$ http://dx.doi.org/doi:10.1590/S0100204X2008000100019>. Acesso em 18 fev. 2010. doi: $10.1590 / \mathrm{S} 0100-204 \mathrm{X} 2008000100019$.

FERNANDES, A.M. et al. Relationship between the somatic cell count in raw milk and the casein fractions of UHT milk. Australian Journal of Dairy Technology, v.63, p.45-49, 2008b.

[IAL] INSTITUTO ADOLFO LUTZ. Normas analíticas do Instituto Adolfo Lutz. 3.ed. São Paulo, IAL, 1985. 533p.

KENNEDY, A.; KELLY, A.L. The influence of somatic cell count on the heat stability of bovine milk plasmin activity. International Dairy Journal, v.7, p.717-721, 1997. Disponível em: <http://dx.doi.org/doi:10.1016/S0958-6946(97)00094-0>. Acesso em 18 fev. 2010. doi:10.1016/S0958-6946(97)00094-0.

KORYCKA-DAHL, M.B. et al. Plasmin activity in milk. Journal Dairy Science, v.66, p.704-711, 1983. Disponível em: <http:/ /dx.doi.org/doi:10.3168/jds.S0022-0302(83)81848-7>. Acesso em 15 fev. 2010. doi:10.3168/jds.S0022-0302(83)81848-7.
MANJI, B. et al. Effect of storage temperature on age gelation of ultra-high temperature milk processed by direct and indirect heating systems. Journal Dairy Science, v.69, p.2994-3001, 1986. Disponível em: <http://dx.doi.org/doi:10.3168/jds.S00220302(86)80761-5>. Acesso em 18 fev. 2010. doi:10.3168/ jds.S0022-0302(86)80761-5.

MUIR, D.D. The shelf-life of dairy products: 1 . factors influencing raw milk and fresh products. Journal of the Society of Dairy Technology, v.49, p.24-32, 1996. Disponível em: <http:// dx.doi.org/doi:10.1111/j.1471-0307.1996.tb02616.x>. Acesso em 15 fev. 2010. doi:10.1111/j.1471-0307.1996.tb02616.x.

PIERZCHALA, P.A. et al. A new fluorogenic substrate for plasmin. Biochemistry Journal, v.183, p.555-559, 1979. Disponível em: <http://www.ncbi.nlm.nih.gov/pmc/articles/ PMC1161636/pdf/biochemj00451-0082.pdf>. Acesso em 18 fev. 2010.

POLITIS, I. et al. Distribution of plasminogen and plasmin in fractions of bovine milk. Journal of Dairy Science, v.75, p.1402-1410, 1992. Disponível em: <http://dx.doi.org/ doi:10.3168/jds.S0022-0302(92)77893-X>. Acesso em 18 fev. 2010. doi:10.3168/jds.S0022-0302(92)77893-X.

RENEAU, J.K.; PACKARD, V.S. Monitoring mastitis, milk quality and economic losses in dairy fields. Dairy, Food and Environmental Sanitation, v.11, p.4-11, 1991.

RICHARDSON, B.C. The proteinases of bovine milk and the effect of pasteurization on their activity. New Zealand Journal of Dairy Science and Technology, v.18, p.233$245,1983$.

ROLLEMA, H.S. et al. Spectrophotometric assay of plasmin and plasminogen in bovine milk. Milchwissenschaft, v.38, p.214-217, 1983.

SAINT-DENIS, T. et al. Enzymatic assays for native plasmin, plasminogen and plasminogen activators in bovine milk. Journal of Dairy Research, v.68, p.437-449, 2001. Disponível em: $<$ http://dx.doi.org/doi:10.1017/S0022029901004939>. Acesso em 15 fev. 2010. doi: 10.1017/S0022029901004939.

SAS Institute. SASâ user's guide: statistics. Cary, NC, 2004. 584p

VERDI, R.J.; BARBANO, D.M. Preliminary investigation of the properties of somatic cell proteases. Journal of Dairy Science, v.71, p.534-538, 1988. Disponível em: <http:// dx.doi.org/doi:10.3168/jds.S0022-0302(88)79586-7>.Acesso em 15 fev 2010. doi:10.3168/jds.S0022-0302(88)79586-7

VERDI, R.J.; BARBANO, D.M. Effect of coagulants, somatic cell enzymes, and extracellular bacterial enzymes on plasminogen activation. Journal of Dairy Science, v.74, p.772-782, 1991. Disponível em: <http://dx.doi.org/ doi:10.3168/jds.S0022-0302(91)78224-6>. Acesso em 15 fev. 2010. doi:10.3168/jds.S0022-0302(91)78224-6.

VIDAL-MARTINS, A.M.C. et al. Evolução do índice proteolítico e do comportamento reológico durante a vida de prateleira de leite UAT/UHT. Ciência e Tecnologia de Alimentos, v.25, p.698-704, 2005. Disponível em: <http:// dx.doi.org/ doi: 10.1590/S0101-20612005000400012>. Acesso em 15 fev. 2010. doi: 10.1590/S0101-20612005000400012. 